\title{
Fluvial sediments in the Alagxa Plateau as a dust source: iron mineralogical and geochemical evidence
}

\author{
WANG Youjun ${ }^{1,2}$, JIA Jia $^{2,3^{*}}$, LU Hao $^{3}$, LU Caichen $^{3}$, XIA Dunsheng ${ }^{3}$ \\ ${ }^{1}$ College of Tourism and Environmental Resource, Zaozhuang University, Zaozhuang 277100, China; \\ ${ }^{2}$ College of Geography and Environmental Sciences, Zhejiang Normal University, Zhejiang 321004, China; \\ ${ }^{3}$ College of Earth and Environmental Sciences, Lanzhou University, Lanzhou 730000, China
}

\begin{abstract}
The Alagxa Plateau, in the margin of the northeastern Tibetan Plateau, is one of the most important dust source areas in East Asia, and the widespread sandy desert in the area is important both as a reservoir and a source of eolian silty. The northeastern margin of the Tibetan Plateau is one of the most actively-growing mountain belt on earth, and has large amounts of debris, with masses of fine grained material, which were continuously mobilized and deposited in the Alagxa Plateau by rivers, forming broad alluvial fans. It is possible that the role of fluvial sediments as a source of silty dust in the Alagxa Plateau has been underestimated. In this study, we test this hypothesis by investigating the iron mineralogical and geochemical characteristics of the fluvial sediments and the surface material of the sandy desert in the Alagxa Plateau, and comparing them with paleo-eolian dust deposits (loess) in the adjacent Chinese Loess Plateau (CLP) to investigate the possible linkages among the fluvial sediments, sandy desert and the last glacial loess of the CLP. The results show that sandy desert typically have high contents of goethite, and high ratios of goethite to hematite, similar to the fluvial sediments in the Alagxa Plateau. Based on the major element characteristics, field investigations and the results of previous studies, we found a genetic link between the silt component of the fluvial sediments and the sandy desert in the Alagxa Plateau with high value of $\mathrm{Gt}$ (goethite) and similarity of the $\mathrm{Gt} /(\mathrm{Hm}$ (hematite) $+\mathrm{Gt}$ ) ratio. But the silt component of the sandy desert main come from the adjacent fluvial sediments. The iron mineralogical characteristics $\left(\chi\right.$ (magnetic susceptibility), $\chi_{\mathrm{ARM}}$ (anhysteretic susceptibility), SIRM (saturation isothermal remanent magnetization) and SIRM ${ }_{\mathrm{AF} 100 \mathrm{mT}}$ (SIRM demagnetized at $100 \mathrm{mT}$ )) of the CLP samples overlap with those of the fluvial sediments in the Alagxa Plateau, but there is a mismatch with the sandy desert samples. This suggests that the fluvial sediments are the source of a large amount of silty material which could be transported to the CLP. Therefore, we conclude that the fluvial sediment in the Alagxa Plateau is an important source of eolian silt, which is deposited in downwind region, and that this source has been previously underestimated.
\end{abstract}

Keywords: fluvial sediments; silty dust; sandy dust; iron mineralogical and geochemical characteristic; Alagxa Plateau

Citation: WANG Youjun, JIA Jia, LU Hao, LU Caichen, XIA Dunsheng. 2019. Fluvial sediments in the Alagxa Plateau as a source of atmospheric dust: iron mineralogical and geochemical evidence. Journal of Arid Land, 11(2): 217-227. https://doi.org/10.1007/s40333-019-0125-3

\section{Introduction}

The Alagxa Plateau is one of most important dust source areas in East Asia (Prospero et al., 2002; Washington et al., 2003; Wang et al., 2008). The frequent dust storms in winter and spring transport

*Corresponding author: JIA Jia (E-mail: jiaj@1zu.edu.cn)

Received 2018-04-24; revised 2018-06-09; accepted 2018-08-06

(C) Xinjiang Institute of Ecology and Geography, Chinese Academy of Sciences, Science Press and Springer-Verlag GmbH Germany, part of Springer Nature 2019 
masses of eolian dust to the Chinese Loess Plateau (CLP), eastern China, Japan, Europe and Pacific Ocean (Hsu et al., 2008). The dust together with the associated strong winds, which remove organic matter and nutrient-rich particles from the soil, damages the crop plants and pollutes the atmosphere. The widespread sandy desert sediments in the Badain Jaran Desert, Tengger Desert and Ulan Buh Desert, have been proposed as a major source of the emitted dust (Liu, 1985; Zhang et al., 1993; Sun, 2002a).

Many studies showed that the contribution of fluvial sediments to the emission of silty dust was underestimated (Stevens et al., 2013; Nie et al., 2015; Zhu et al., 2016). One of the most important pieces of evidence supporting this inference is that major deposits of eolian loess are commonly located close to large rivers (Smalley et al., 2009). Smalley et al. (2009) suggested that longdistance fluvial transport of sediments is a critical step in the process of generating material for eolian transport and the subsequent widespread formation of loess deposits across the landscape. In addition, Stevens et al. (2013) and Nie et al. (2015) proposed a genetic link between the CLP and the Yellow River, based on the evidence of U-Pb age distributions and heavy mineral assemblages. In the case of the Alagxa Plateau, geomorphic evidence reveals that there is a transition from an alluvial-lacustrine plain to a Gobi-desert plain in the Ejina Basin (Zhu et al., 2016), which indicates that huge amounts of dust material have been emitted. The adjacent high mountains, such as the Qilian Mountains and Gobi Altay Mountains, are one of the most actively growing mountain belts on earth (Hetzel et al., 2004; Chen and Li, 2013; Tian et al., 2014). The rivers originating in the Qilian Mountains continuously supply sediments to the Alagxa Plateau and the Hexi Corridor, with an annual average weight of about $1.2 \times 10^{7} \mathrm{t}$ (Pan et al., 2010). Thus, this huge potential source of silty dust for aeolian transport needs to be evaluated.

In this study, we test the hypothesis that fluvial sediments potentially make an important contribution to dust emissions by comparing the iron mineralogical and geochemical characteristics of the fluvial sediments and sandy desert in the Alagxa Plateau with the loess deposits downwind in the CLP.

\section{Materials and methods}

\subsection{Study area}

The Alagxa Plateau is located in the northwest of CLP $\left(37^{\circ} 30^{\prime}-42^{\circ} 36^{\prime} \mathrm{N}, 93^{\circ} 06^{\prime}-106^{\circ} 36^{\prime} \mathrm{E}\right.$; Fig. 1). The plateau has an area of $2.5 \times 10^{5} \mathrm{~km}^{2}$, with the Yellow River and Helan Mountains to the east and southeast, the Qilian Mountains to the south and southwest, and the Beishan Mountains to the west. The Alagxa plateau is mainly occupied by Gobi and sandy desert (80\%-90\%). The two principal geomorphic units are the Badain Jaran Desert and the Tengger Desert, at which the Heihe River and Shiyang River terminate, respectively. Both river systems have developed vast alluvial fans, mainly covered by gravel deposits. This area is characterized by an arid temperate and desert climate, with precipitation seldom exceeding $150 \mathrm{~mm}$ and high potential evaporation exceeding $2500 \mathrm{~mm}$ (Chen and Qu, 1992).

The Jiuzhoutai is located in the western CLP and close to the Alagxa Plateau. Dust storms, observed by satellites, occurred frequently during winter and spring seasons, and transported large amounts of dust from the Alagxa Plateau to the Jiuzhoutai area (Sun, 2002a).

\subsection{Sampling}

Fluvial sediments include modern/ancient flood plain, alluvial fan and lacustrine sediment. We selected 24 sampling sites for the fluvial sediments in this study, including 20 for the Heihe River (HR-01-HR-20) and 4 for the Shiyang River (SYH-01-SYH-04). About 3-10 samples were collected from each sampling sites, having 178 samples in total. Meanwhile, we selected 18 sampling sites for the sandy desert (D-01-D-18; 1 sample from each sampling site) and 1 sampling site for the last glacial loess of the CLP (in the Jiuzhoutai area; 4 samples from this site: L-01-L04). Due to the arid climatic conditions, the last glacial loess of the CLP is minimally affected by pedogenesis and retains its lithological characteristics (Jia et al., 2015). All the sampling sites are far away from roads, farmland, villages and towns, to avoid the influence of vehicular pollution 
and human activities.

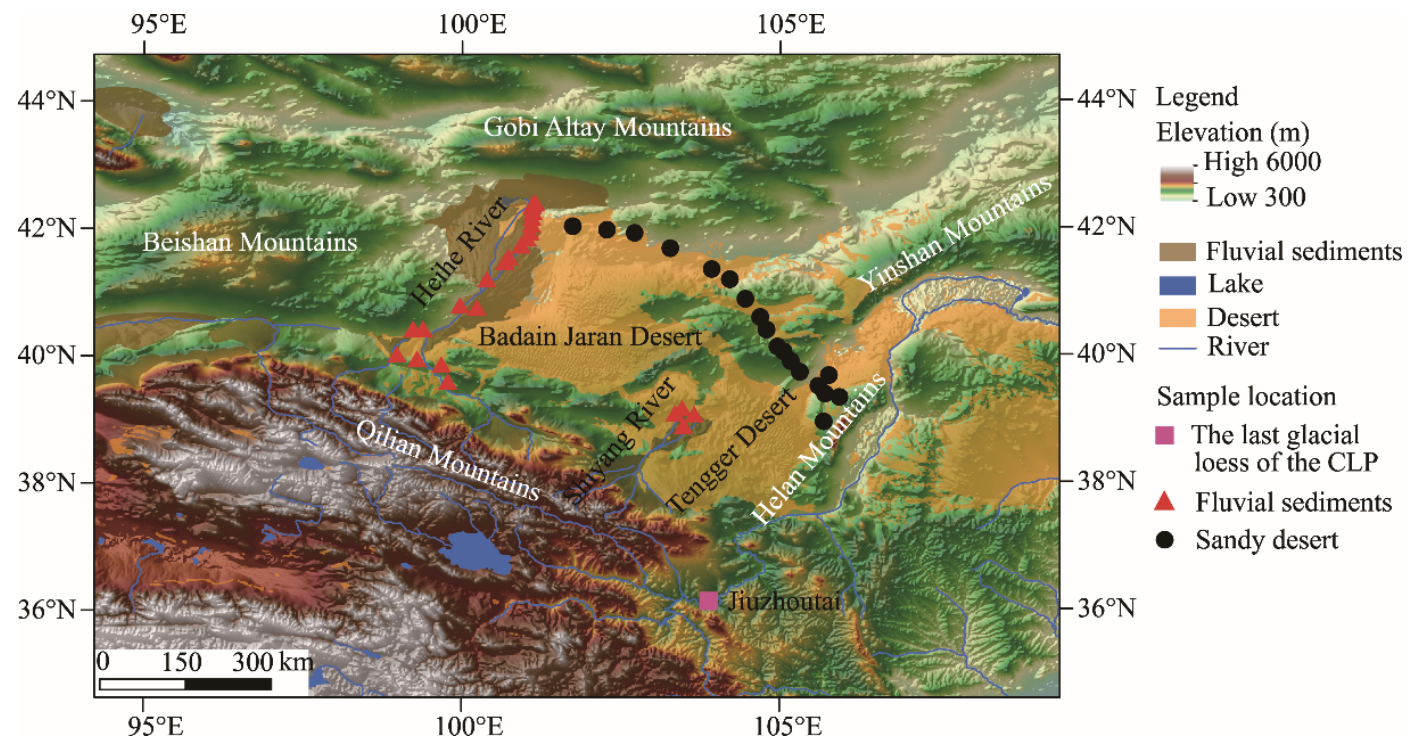

Fig. 1 Location and geological setting of the Alagxa Plateau and the distributions of the sampling sites for the fluvial sediments in the Heihe River (HR-01-HR-20) and Shiyang River (SYH-01-SYH-04), the sandy desert (D01-D-18) and the last glacial loess of the Chinese Loess Plateau (CLP)

\subsection{Data analyses}

Magnetite/maghemite, hematite (Hm) and goethite (Gt) are the three most important iron minerals in most natural sediments. Among them, magnetite/maghemite has strong magnetic properties with high magnetic properties susceptibility $(\chi)$, and is typically present in trace amounts. $\mathrm{Hm}$ and $\mathrm{Gt}$ have weak magnetic with low $\chi$, but may be much more abundant on a mass basis than magnetite/maghemite. Therefore, a combination of magnetic measurements and diffuse reflectance spectroscopy (DRS) were selected to investigate the iron mineralogical characteristics of the samples.

In the laboratory, all samples were subject to the following fractionation procedures. After air drying, any particles greater than $1000 \mu \mathrm{m}$ (mainly consisting of fine gravel and plant material) were sieved out. The remaining material was separated into two fractions by sieving. The fraction $\leq 63 \mu \mathrm{m}$ was used for the laboratory analyses described below, and the fraction $>63 \mu \mathrm{m}$ was retained for visual inspection. The grain-size distribution of the $\leq 63 \mu \mathrm{m}$ fraction of the fluvial sediments is very similar to that of sandy desert which have a modal size range of 3-20 $\mu \mathrm{m}$. This suggests that the effects of grain-size sorting on various parameters are minor (Fig. 2). Furthermore, the bimodal grain-size distribution of the typical loess of the CLP indicates that the fine-grained components have a similar modal size range to the fluvial and desert sediments (Sun et al., 2004; Qiang et al., 2016).

\subsubsection{Magnetic measurements}

$\chi$ is commonly used to assess the bulk concentration of ferrimagnetic mineral in the natural samples, and is also particularly sensitive to the content of superparamagnetic (SP) grains ( $<30 \mathrm{~nm}$; Thompson and Oldfield, 1986). Anhysteretic susceptibility $\left(\chi_{\mathrm{ARM}}\right)$ is sensitive to the concentration of ferrimagnetic minerals in the single domain range. SIRM (saturation isothermal remanent magnetization) and related demagnetization ratios provide estimates of the total content of remanence-bearing material and the relative proportions of low coercivity (ferrimagnetic) and high coercivity (imperfect antiferromagnetic) magnetic phases. SIRM ${ }_{\mathrm{AF} 100 \mathrm{mT}}$ (SIRM demagnetized at $100 \mathrm{mT}$ ) is a remanent parameter which cleans the magnetic signal of the ferrimagnetic contribution and is often used as a rough indicator of the concentration of antiferromagnetic minerals. 


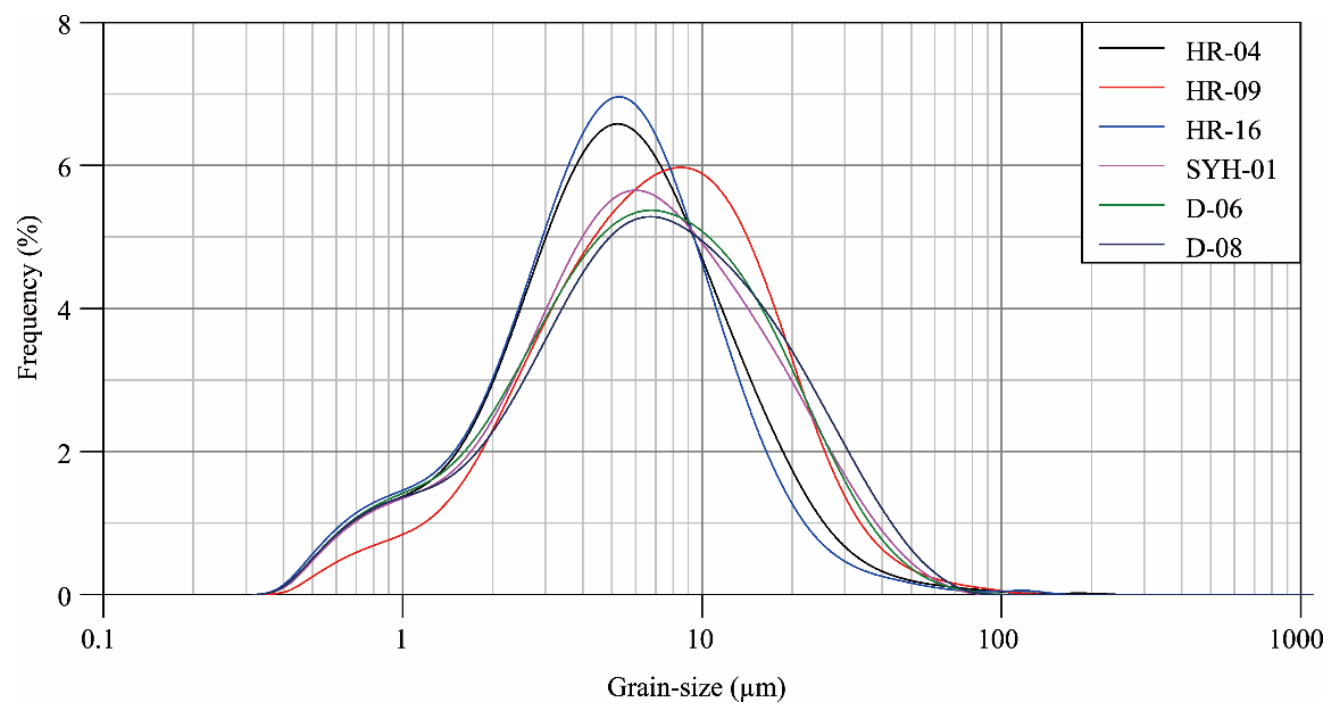

Fig. 2 Grain-size frequency distributions of the representative sampling sites for the fluvial sediments in the Heihe River (HR-04, HR-09 and HR-16) and Shiyang River (SYH-01) and for the sandy desert (D-06 and D-08)

Samples ( $\leq 63 \mu \mathrm{m}$ fraction) were packed in $10 \mathrm{ml}$ plastic pots and then subjected to the following series of magnetic measurements. Mass-specific $\chi$ was measured with a Bartington MS2 meter and MS2B sensor (470 Hz; Bartington Instruments Ltd, British). Anhysteretic remanent magnetization (ARM) was imparted with a DTECH AF demagnetizer (2G Enterprises, US) at a peak AF field of $80 \mathrm{mT}$ and a DC bias field of $100 \mu \mathrm{T}$, and measured using a 2G Enterprises Superconducting Rock Magnetometer (2G-755). ARM is expressed as an anhysteretic susceptibility ( $\left.\chi_{\mathrm{ARM}}\right)$ by dividing the biasing field strength. SIRM was imparted at 1T using an MMPM10 Impulse Magnetizer (JR6 spinner magnetometer, AGICO, Czechoslovakia), then demagnetized at $100 \mathrm{mT}\left(\mathrm{SIRM}_{\mathrm{AF} 100 \mathrm{mT}}\right)$ and measured again.

\subsubsection{DRS measurements}

Samples $(\leq 63 \mu \mathrm{m}$ fraction) for DRS measurements were mixed with distilled water, and the resulting slurry was smeared on a glass microscope slide, smoothed and then dried slowly at room temperature. The samples were analyzed using a Perkin Elmer Lambda 900 spectrophotometer (Perkin Elmer, US) to obtain the DRS spectra over the range of 400-700 $\mathrm{nm}$ at a 2-nm interval. Reflectance data were processed to obtain percentage reflectance in standard color bands (violet, 400-450 nm; blue, 450-490 nm; green, 490-560 nm; yellow, 560-590 nm; orange, 590-630 nm; and red, 630-700 nm) (Judd and Wyszecki, 1975). We calculated the red percentage reflectance (redness) by dividing the percentage of red reflectance in a band by the total visible wavelength reflectance in the samples, following the method of Long et al. (2011). The Hm content was estimated from the redness $\%$ using a linear regression model: $\mathrm{Hm} \%=0.05 \times$ redness $\%-1.15$. Iron (Fe) was extracted using the citrate/bicarbonate/dithionite method as free iron oxides (Fed) (Mehra and Jackson, 1960), which were measured using an atomic absorption spectrometer AA240 (Varian, American) with a relative error of $1 \%$. The Gt content was estimated using the formula: $\mathrm{Gt} \%=1.59 \times(\mathrm{Fed}-\mathrm{Hm} \% / 1.43)$ (Torrent et al., 2007).

\subsubsection{Major elements analyses}

Samples ( $\leq 63 \mu \mathrm{m}$ fraction) for major elements (Si, silicon; Al, aluminum; Fe, iron; Ti, titanium; $\mathrm{Ca}$, calcium; $\mathrm{Mg}$, magnesium; $\mathrm{Na}$, sodium; and $\mathrm{K}$, kalium) analyses were prepared by pouring the measured weight of sediment (about $4 \mathrm{~g}$ ) into the center of a column apparatus, together with boric acid, and then pressurizing under $30 \mathrm{t} / \mathrm{m}^{2}$ for $20 \mathrm{~s}$. The resulting sample of approximately $4 \mathrm{~cm}$ in diameter and $8 \mathrm{~mm}$ in thickness was analyzed using a MagixPW2403 X-ray fluorescence spectroscope (PANalytical, Holland). The standard deviation based on repeat sample analysis was approximately $2 \%$. 


\section{Results}

\subsection{Magnetic measurements}

Table 1 summarizes the values of the magnetic parameters of all samples. $\chi$ values of the fluvial sediment samples $\left(10 \times 10^{-8}-49 \times 10^{-8} \mathrm{~m}^{3} / \mathrm{kg} ; 27 \times 10^{-8}\left( \pm 8 \times 10^{-8}\right) \mathrm{m}^{3} / \mathrm{kg}\right)$ were more lower than those of the sandy desert samples $\left(70 \times 10^{-8}-334 \times 10^{-8} \mathrm{~m}^{3} / \mathrm{kg} ; 174 \times 10^{-8}\left( \pm 83 \times 10^{-8}\right) \mathrm{m}^{3} / \mathrm{kg}\right)$. The content of fine-grained ferrimagnetic material and imperfect antiferromagnetic material, indicated by the $\chi_{\mathrm{ARM}}$ and $\mathrm{SIRM}_{\mathrm{AF} 100 \mathrm{mT}}$ values, were also higher in the sandy desert than those in the fluvial sediments. The overall magnetic characteristics of the last glacial loess samples of the CLP were similar to those of the fluvial sediments.

Table 1 Descriptive statistics for magnetic parameters of the fluvial sediments and sandy desert in the Alagxa Plateau and the last glacial loess of the Chinese Loess Plateau (CLP)

\begin{tabular}{|c|c|c|c|c|c|}
\hline \multirow{2}{*}{\multicolumn{2}{|c|}{ Sediment type }} & $\chi$ & $\chi_{\text {ARM }}$ & SIRM & $\mathrm{SIRM}_{\mathrm{AF} 100 \mathrm{mT}}$ \\
\hline & & \multicolumn{2}{|c|}{$\left(\times 10^{-8} \mathrm{~m}^{3} / \mathrm{kg}\right)$} & \multicolumn{2}{|c|}{$\left(\times 10^{-5} \mathrm{Am}^{2} / \mathrm{kg}\right)$} \\
\hline \multirow{4}{*}{$\begin{array}{l}\text { Fluvial sediments } \\
\qquad(n=178)\end{array}$} & $\operatorname{Max}$ & 49 & 91 & 738 & 109 \\
\hline & Min & 10 & 27 & 218 & 41 \\
\hline & Mean & 27 & 54 & 443 & 81 \\
\hline & SD & 8 & 13 & 154 & 17 \\
\hline \multirow{4}{*}{$\begin{array}{l}\text { Sandy desert } \\
\quad(n=18)\end{array}$} & Max & 334 & 298 & 4985 & 525 \\
\hline & Min & 70 & 126 & 1185 & 163 \\
\hline & Mean & 174 & 183 & 2454 & 294 \\
\hline & $\mathrm{SD}$ & 83 & 51 & 1037 & 112 \\
\hline $\begin{array}{l}\text { The last glacial loess of the } \\
\text { CLP }(n=4)\end{array}$ & Mean & 35 & 56 & 652 & 105 \\
\hline
\end{tabular}

Note: $\chi$, magnetic susceptibility; $\chi_{\mathrm{ARM}}$, anhysteretic susceptibility; SIRM, saturation isothermal remanent magnetization; $\mathrm{SIRM}_{\mathrm{AF} 100 \mathrm{mT}}$, SIRM demagnetized at $100 \mathrm{mT}$,

\subsection{Gt and Hm content}

Gt and $\mathrm{Hm}$ are two widely distributing iron minerals in the surface sediments (Oldfield et al., 2014). The DRS results indicated that most of the fluvial sediment samples contained more than $10.0 \%$ Gt $(n=22 ; 13.0 \%$ o $( \pm 4.0 \%))$ and $2.5 \%$ Hm $(n=22 ; 3.3 \%$ o $( \pm 0.9 \%$ o $)$ (Fig. 3$)$. The Gt content of the sandy desert samples was low, with a range of $4.0 \% 0-16.0 \%$ o $(n=7 ; 11.0 \%$ o $( \pm 4.0 \% 0))$. However, the $\mathrm{Hm}$ content of the sandy desert samples was high, with a range of $2.9 \%{ }^{-}-5.4 \%$ o $(n=7 ; 3.8 \%$ o $( \pm 0.8 \%$ ) $)$. The last glacial loess samples of the CLP contained $11.4 \%$ ot and $3.2 \% \mathrm{Hm}$, which were lower than those of the fluvial sediments.

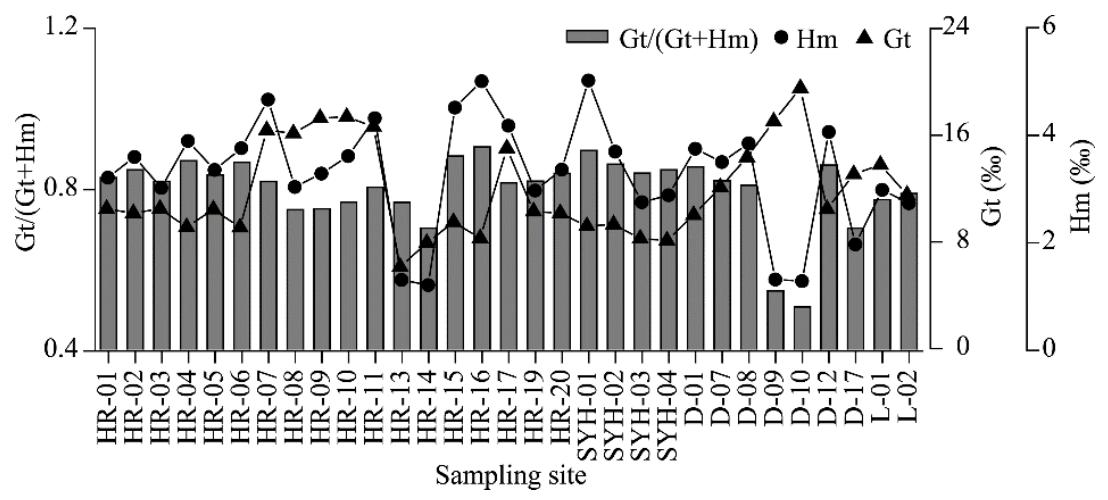

Fig. 3 Contents of goethite $(\mathrm{Gt})$ and hematite $(\mathrm{Hm})$ of the fluvial sediments in the Heihe River and Shiyang River, the sandy desert and the last glacial loess of the CLP

The $\mathrm{Gt} /(\mathrm{Gt}+\mathrm{Hm})$ ratios of the fluvial sediment samples $(0.79( \pm 0.06))$ were similar to those of the last glacial loess of the CLP (Mean=0.78), while the values of the sandy desert samples were 
slightly lower $(0.72( \pm 0.38))$. It should be noted that most of the sandy desert samples exhibited similar values with those of the other two sediment types, except for two sampling sites (D-09 and D-10). If samples from these two sampling sites are eliminated, the average $\mathrm{Gt} /(\mathrm{Gt}+\mathrm{Hm})$ ratio of the sandy desert samples was 0.79 .

\subsection{Element contents}

Contents of the selected major elements ( $\mathrm{Si}, \mathrm{Al}, \mathrm{Fe}, \mathrm{Ti}, \mathrm{Ca}, \mathrm{Mg}, \mathrm{Na}$ and $\mathrm{K}$ ) of the fluvial sediments, sandy desert and the last glacial loess of the CLP are illustrated in Figure 4. In contrast to the two other sediment types, the fluvial sediments had lower $\mathrm{Si}$ and $\mathrm{Ti}$ contents, and higher $\mathrm{Mg}$ and $\mathrm{Ca}$ contents, and the values were tightly clustered irrespective of the sample locations. Notably, the $\mathrm{Ca}$ content of the fluvial sediments was highly variable, ranging from $4.5 \%$ to $34.7 \%(\mathrm{SD}=7.4)$. The sandy desert is characterized by higher $\mathrm{Si}$ and $\mathrm{Ti}$ contents and lower $\mathrm{Ca}$ contents, compared with the other two sediment types.
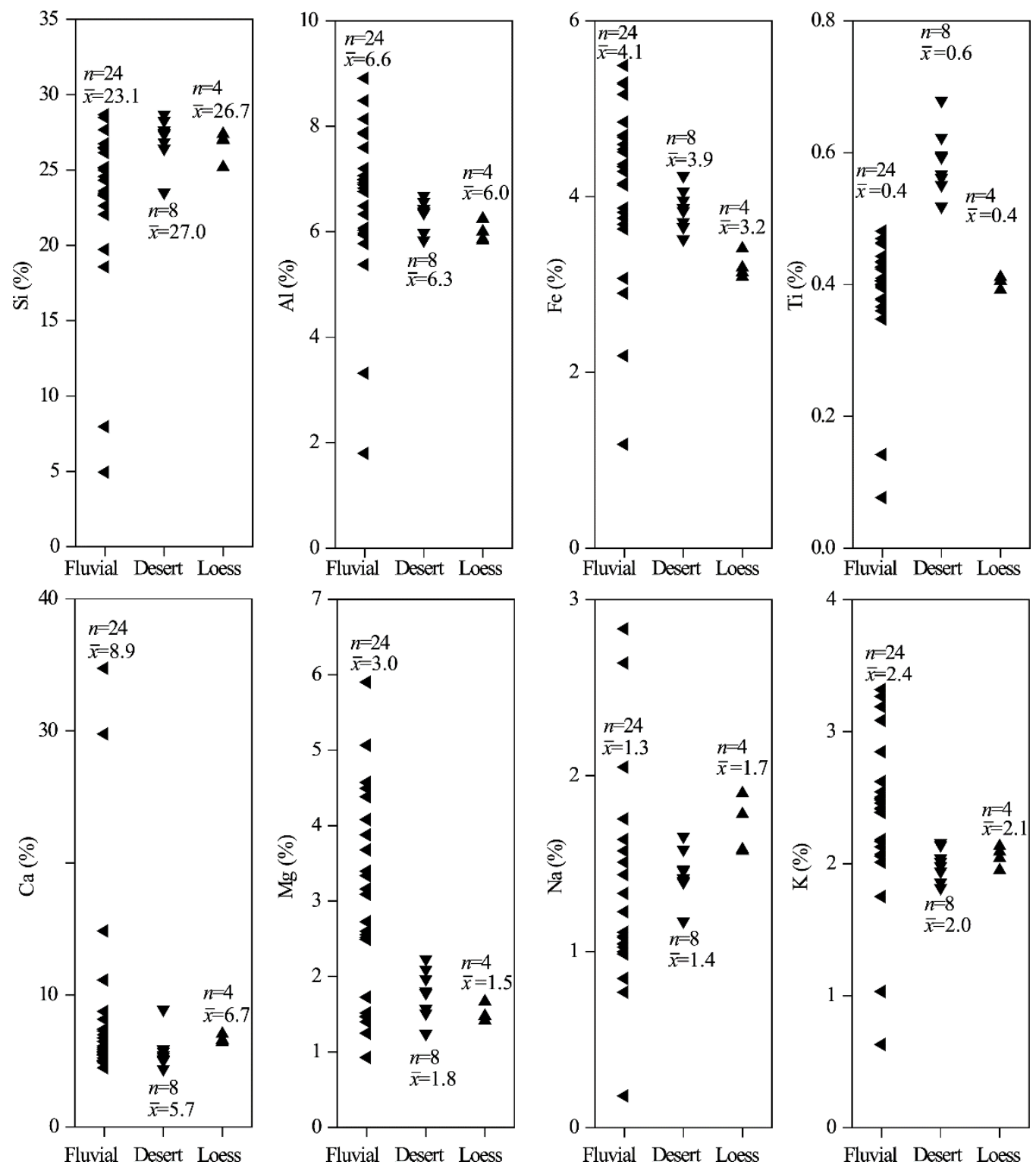

Fig. 4 Contents of the selected major elements ( $\mathrm{Si}$, silicon; $\mathrm{Al}$, aluminum, $\mathrm{Fe}$, iron; Ti, titanium; $\mathrm{Ca}$, calcium; $\mathrm{Mg}$, magnesium; Na, sodium; and $\mathrm{K}$, kalium) of the fluvial sediments (Fluvial), sandy desert (Desert) and the last glacial loess of the CLP. 


\section{Discussion}

\subsection{The role of silt in linking fluvial sediments and sandy desert material in the Alagxa Plateau}

In Eastern Asia, two main factors controlling the production of silty material are climaticallycontrolled glacial grinding and denudation induced by tectonic uplift (Sun, 2002a). The desert serves as a store or reservoir of the fine-grained material produced in the adjacent mountains by these processes (Smalley et al., 2009). In addition, rivers play an important role in transporting the silty material from the high mountains to the alluvial-desert plain (Smalley et al., 2009). Subsequently, the Asian winter monsoon transports the particles downwind to desert basins and the CLP (Sun, 2002b). The point of this view is supported by an increasing amount of geological evidence, especially the age distribution of detrital zircon U-Pb ages. Probability density plots have been produced for the detrital zircon U-Pb ages of the fluvial sediments and sandy desert in the Alagxa Plateau and the loess of the CLP (Che and Li, 2013; Zhang et al., 2015; Nie et al., 2018). Zircon is highly stable at the earth surface so that the U-Pb isotopic within system is similar. The age population of detrital zircon grains can reflect the multiple stage of rock formation in the source regions and they are therefore a useful sediment tracer. Age distributions analysis of the detrital zircon indicates a common source for the silt component of the fluvial sediments and sandy desert in the Alagxa Plateau and the loess of the CLP (Che and Li, 2013; Zhang et al., 2015; Nie et al., 2018).

The results of the present study provide further evidence for a genetic link between the silty component of the fluvial sediments and sandy desert in the Alagxa Plateau. Gt production tends to be favored by a moist and low $\mathrm{pH}$ environment, while in contrast, $\mathrm{Hm}$ production is favored by a hot environment (Schwertmann, 1985). The similarity of the $\mathrm{Gt} /(\mathrm{Hm}+\mathrm{Gt})$ ratios between the fluvial sediments and sandy desert in the Alagxa Plateau suggests that their silt components are formed under moist conditions. It is hot and dry in the desert climate of the Alagxa Plateau, and the silt component of the sandy desert cannot be autochthonous. The adjacent fluvial sediments are the only potential source which can continuously produce the large amounts of silty material. In addition, a scatter plot of stable element ratios (Fig. 5) shows that the sandy desert samples investigated in this study overlap with or located near the regression line for the fluvial sediment samples in the Heihe River. This also suggests a genetic link between the fluvial sediments and sandy desert in the Alagxa Plateau.
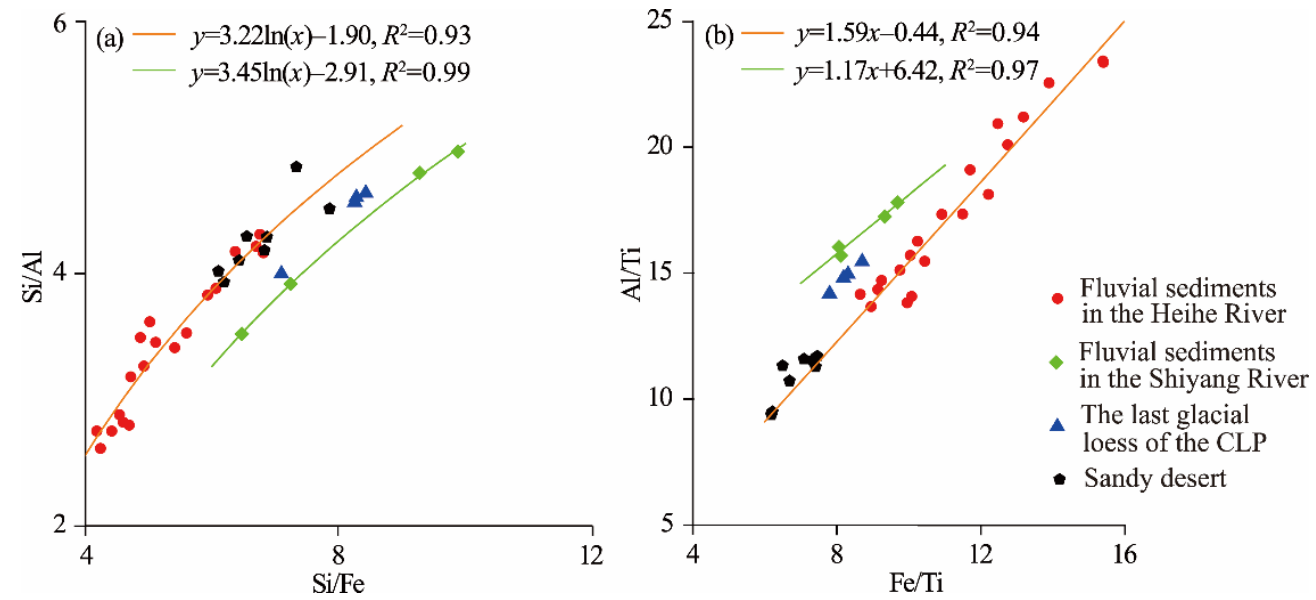

Fig. 5 Scatter plots of major element ratios for the fluvial sediments and sandy desert in the Alagxa Plateau and the last glacial loess of the CLP

The modern landscape also supports a genetic link between the fluvial sediments and sandy desert in the Alagxa Plateau. First, the Heihe River and Shiyang River both originate from the Qilian Mountains and transport large amounts of debris to mountain piedmonts and basin 
depressions in the Alagxa Plateau, forming vast flat alluvial fans (Pan et al., 2010). Combined with the arid conditions, strong northwest wind preferentially erode the silt and sand fractions of the sediments, leaving a gravel cover on the alluvial fan surface. Therefore, from the Alagxa Plateau in the northwest to the CLP in the southeast, the deposits exhibit a zonal distribution on the CLP, consisting of the following sequence: gravel (Gobi), sand (sandy desert) and silt (loess). Second, several modern sand dunes are developing within the fluvial sand deposits around Gobi areas (Figs. 6a and b; Zhu et al., 2016). Third, the widespread yardangs, deflation hollows and Gobi suggest that huge amounts of fine-grained material have been eroded from the fluvial sediments (Figs. 6bd).

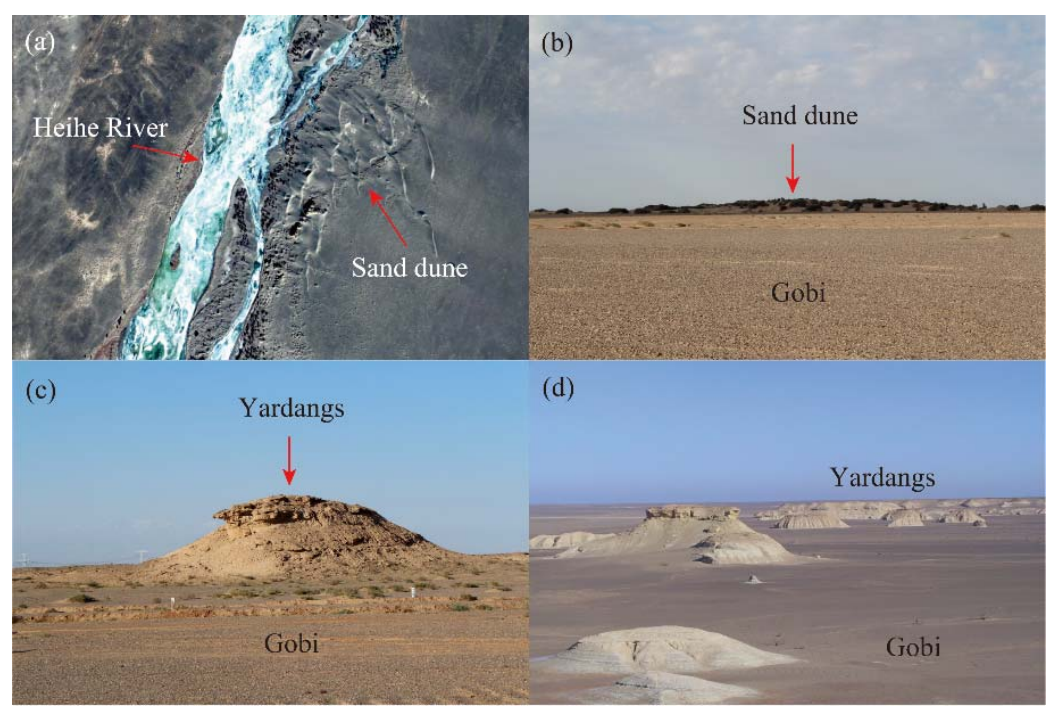

Fig. 6 Remote sensing image of the Heihe River and the nearby sand dune (a), typical reg of clasts developed on the alluvial plain and the nearby sand dune (b), and Yardangs and Gobi in the Heihe River Basin (c and d)

\subsection{Link between the silt component of the fluvial sediments in the Alagxa Plateau and the last glacial loess of the CLP}

The magnetic properties of ferrimagnetic minerals depend greatly on grain-size, in addition, previous studies have shown that magnetite grains are sensitive to wind sorting (Begét et al., 1990; Song et al., 2010; Zan et al., 2011; Wei et al., 2013; Zan et al., 2015). Wei et al. (2013) proposed that density difference between minerals with different magnetic properties was a major cause of spatial differences in the $\chi$ of eolian deposits. Typically, ferrimagnetic and imperfect antiferromagnetic minerals, such as magnetite, maghemite and $\mathrm{Hm}$, which are relatively strongly magnetic, have a higher density than weakly magnetic paramagnetic and diamagnetic minerals, such as quartz, feldspar and calcite. Therefore, strongly magnetic minerals tend to be enriched in deposits which have been transported a relatively short distance from the source.

Figure 7 shows a series of scatter plots for selected magnetic parameters for the three sediment types (fluvial sediments and sandy desert in the Alagxa Plateau and the last glacial loess of the CLP). The magnetic properties of the fluvial sediments samples were more variable than those of other sediment samples, but they overlapped with those of the loess samples. The sandy desert samples exhibited strong linear relationships between magnetic parameters but there was a minimal overlap with the last glacial loess of CLP and fluvial sediment samples. In addition, the sandy desert samples were enriched in strongly magnetic minerals. Our field investigations revealed that the fluvial sediments contained much higher proportions of fine grained material than the sandy desert samples (Fig. 6). The results of laboratory measurements showed that the $\leq 63 \mu \mathrm{m}$ fractions comprised up to $71.4 \%$ of the fluvial sediments, but only $8.1 \%$ of the sandy desert samples (Fig. 8 ). Therefore, we propose that the silty material in the sandy desert is well-sorted and has been transported by wind and deposited close to the source, and that a proportion of the silt component of the fluvial sediments is transported to the CLP. 

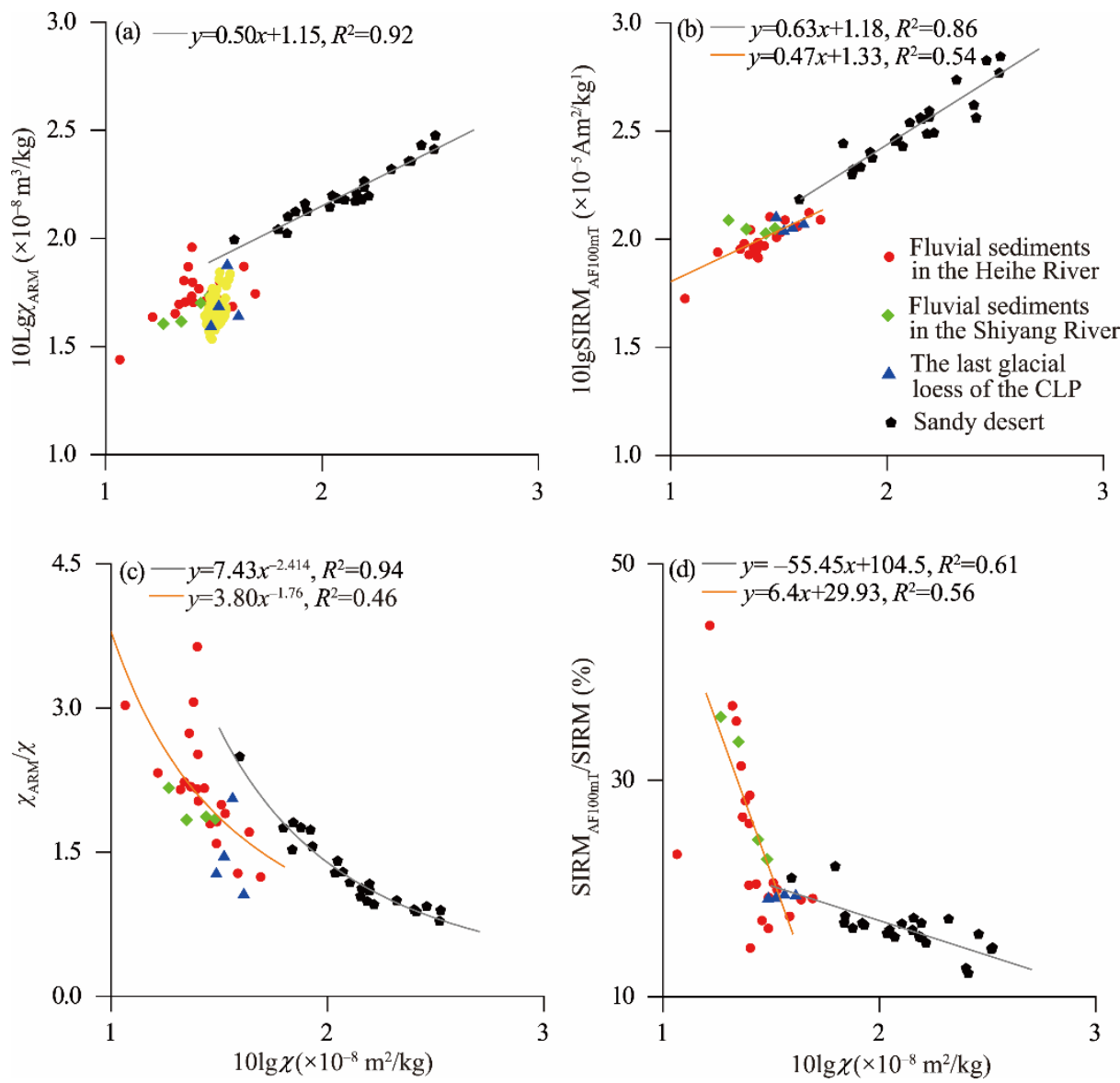

Fig. 7 Scatter plots of magnetic parameters for samples of the fluvial sediments and sandy desert in the Alagxa Plateau and the last glacial loess of the CLP. $\chi$, magnetic susceptibility; $\chi$ ARM, anhysteretic susceptibility; SIRM, saturation isothermal remanent magnetization; $\mathrm{SIRM}_{\mathrm{AF} 100 \mathrm{mT}}$, SIRM demagnetized at $100 \mathrm{mT}$.

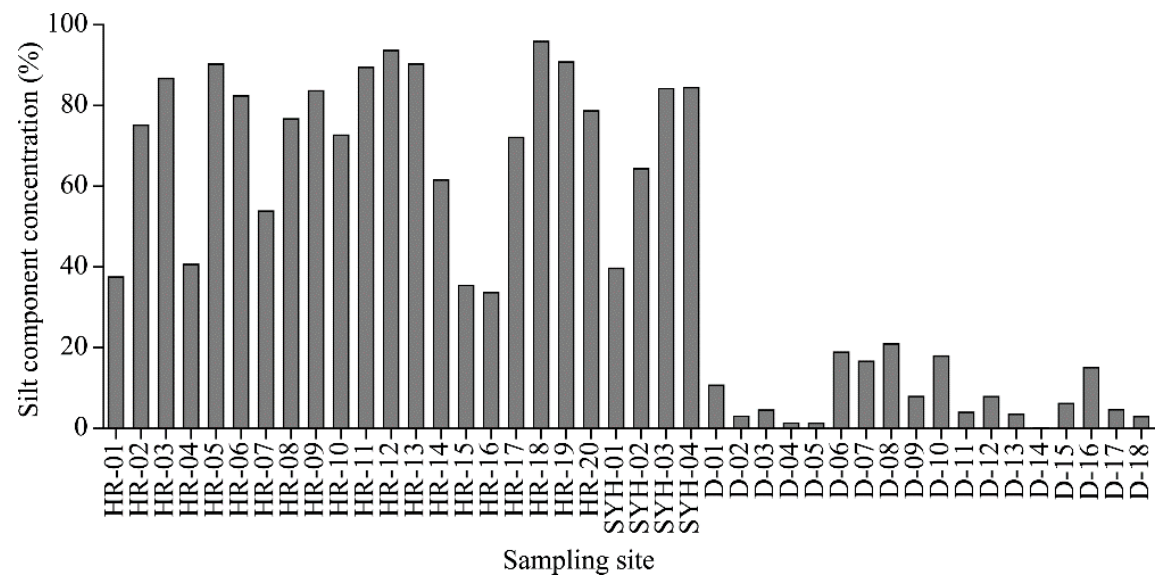

Fig. 8 Silt components of the fluvial sediments in the Heihe River and Shiyang River and the sandy desert

\section{Conclusions}

The fluvial sediments and sandy desert material in the Alagxa Plateau have obvious different iron mineralogical and geochemical characteristics. The fluvial sediments are characterized by a wide range of major element contents and low contents of strongly magnetic minerals. The sandy desert 
has higher contents of Ti and strongly magnetic minerals. The last glacial aeolian deposits of the CLP exhibit similar iron mineralogical characteristics with the fluvial sediments in the Alagxa Plateau, but have a much narrower range of major element contents, which suggests that loess is a well-mixed eolian dust.

Our experimental results, supported by geomorphological evidence and the results of previous studies, indicate that the fluvial sediments are the dominant source of eolian silt emitted in the Alagxa Plateau, which is then transported long distance downwind. In addition, although there is a genetic link between the sandy desert material and fluvial sediments in the Alagxa Plateau, the contribution of sandy desert material to the eolian silt is limited.

\section{Acknowledgements}

This study was supported by the National Natural Science Foundation of China (41401046) and the Fundamental Research Funds for the Central Universities (lzujbky-2016-264, lzujbky-2016-bt01). We thank Dr. Jan BLOEMENDAL for critical discussions, constructive suggestions and English language improvement.

\section{References}

Begét J E, Stone D B, Hawkins D B. 1990. Paleoclimatic forcing of magnetic susceptibility variations in Alaskan loess during the late Quaternary. Geology, 18(1): 40-43.

Che X D, Li G J. 2013. Binary sources of loess on the Chinese Loess Plateau revealed by U-Pb ages of zircon. Quaternary Research, 80(3): 545-551.

Chen L H, Qu Y G. 1992. Water and Land Resources and Their Rational Development and Utilization in the Hexi Region. Beijing: Science Press, 60-100. (in Chinese)

Chen Z, Li G J. 2013. Evolving sources of eolian detritus on the Chinese Loess Plateau since early Miocene: Tectonic and climatic controls. Earth and Planetary Science Letters, 371-372(2): 220-225.

Hetzel R, Tao M X, Stokes S, et al. 2004. Late Pleistocene/Holocene slip rate of the Zhangye thrust (Qilian Shan, China) and implications for the active growth of the northeastern Tibetan Plateau. Tectonics, 23(6-TC6006): 1-17.

Hsu S C, Liu S C, Huang Y T, et al. 2008. A criterion for identifying Asian dust events based on Al concentration data collected from northern Taiwan between 2002 and early 2007. Journal of Geophysical Research, 113, D18306, doi: 10.1029/2007JD009574.

Jia J, Xia D S, Wang Y J, et al. 2015. East Asian monsoon evolution during the Eemian, as recorded in the western Chinese Loess Plateau. Quaternary International, 399: 156-164.

Judd D B, Wyszecki G. 1975. Color in Business, Science, and Industry. New York: John Wiley, 503-565.

Liu T S. 1985. Loess and the Environment. Beijing: China Ocean Press, 2-79.

Long X Y, Ji J F, William B. 2011. Rainfal-dependent transformations of iron oxides in a tropical saprolite transect of Hainan Island, South China: Spectral and magnetic measurements. Journal of Geophysical Research Atmospheres, 116(F3): $239-255$.

Mehra O P, Jackson M L. 1960. Iron oxide removal from soils and clays by a dithionite-citrate system buffered with sodium bicarbonate. Clays Clay Miner, 7(1): 317-327.

Nie J S, Stevens T, Rittner M, et al. 2015. Loess Plateau storage of Northeastern Tibetan Plateau-derived Yellow River sediment. Nature Communications, 6(1): 8511, doi: 10.1038/ncomms9511.

Nie J S, Pullen A, Garzione C N, et al. 2018. Pre-Quaternary decoupling between Asian aridification and high dust accumulation rates. Science Advances, 4(2): eaao6977, doi: 10.1126/sciadv.aao6977.

Oldfield F, Chiverrell R C, Lyons R, et al. 2014. Discriminating dusts and dusts sources using magnetic properties and hematite: Goethite ratios of surface materials and dust from North Africa, the Atlantic and Barbados. Aeolian Research, 13(13): 91-104.

Pan B T, Geng H P, Hu X F, et al. 2010. The topographic controls on the decadal-scale erosion rates in Qilian Shan Mountains, N.W. China. Earth and Planetary Science Letters, 292(1-2): 148-157.

Prospero J M, Ginoux P, Torres O, et al. 2002. Environmental characterization of global sources of atmospheric soil dust identified with the Nimbus 7 total ozone mapping spectrometer (TOMS) absorbing aerosol product. Reviews of Geophysics, 40(1): 1002.

Qiang M R, Jin Y X, Liu X X, et al. 2016. Late Pleistocene and Holocene aeolian sedimentation in Gonghe Basin, northeastern Qinghai-Tibetan Plateau: Variability, processes, and climatic implications. Quaternary Science Reviews, 132: 57-73.

Schwertmann U. 1985. Formation of Secondary Iron Oxides in Various Environments. Paris: D.Reidel Publishing Company.

Smalley I J, O'Hara-Dhand K, Wint J, et al. 2009. Rivers and loess: The significance of long river transportation in the complex event-sequence approach to loess deposit formation. Quaternary International, 198(1-2): 7-18. 
Song Y G, Shi Z T, Fang X M, et al. 2010. Loess magnetic properties in the Ili Basin and their correlation with the Chinese Loess Plateau. Science China Earth Sciences, 53(3): 419-431. (in Chinese)

Stevens T, Carter A, Watson T P, et al. 2013. Genetic linkage between the Yellow River, the Mu Us desert and the Chinese Loess Plateau. Quaternary Science Reviews, 78(19): 355-368.

Sun D H, Bloemendal J, Rea D K, et al. 2004. Bimodal grain-size distribution of Chinese loess, and its palaeoclimatic implications. Catena, 55(3): 325-340.

Sun J M. 2002a. Provenance of loess material and formation of loess deposits on the Chinese Loess Plateau. Earth and Planetary Science Letters, 203(3-4): 845-859.

Sun J M. 2002b. Source regions and formation of the loess sediments on the high mountain regions of northwestern China. Quaternary Research, 58(3): 341-351.

Thompson R, Oldfield F. 1986. Environmental Magnetism. London: Allen and Unwin.

Tian Z H, Xiao W J, Windley B F, et al. 2014. Structure, age, and tectonic development of the Huoshishan-Niujuanzi ophiolitic mélange, Beishan, southernmost Altaids. Gondwana Research, 25(2): 820-841.

Torrent J, Liu Q S, Bloemendal J, et al. 2007. Magnetic Enhancement and Iron Oxides in the Upper Luochuan Loess-Paleosol Sequence, Chinese Loess Plateau. Soil Science Society of America Journal, 71(5): 1570-1578.

Wang X, Huang J P, Ji M X, et al. 2008. Variability of East Asia dust events and their long-term trend. Atmospheric Environment, 42(13): 3156-3165.

Washington R, Todd M, Middleton N J, et al. 2003. Dust-storm source areas determined by the total ozone monitoring spectrometer and surface observations. Annals of the Association of American Geographers, 93(2): 297-313.

Wei H T, Banerjee S K, Xia D S, et al. 2013. Magnetic characteristics of loess-paleosol sequences on the north slope of the Tianshan Mountains, northwestern China and their paleoclimatic implications. Chinese Journal of Geophysics, 56(1): 150158. (In Chinese)

Zan J B, Fang X M, Nie J S, et al. 2011. Magnetic properties of surface soils across the southern Tarim Basin and their relationship with climate and source material. Chinese Sci Bull, 56(3): 290-296.

Zan J B, Fang X M, Nie J S, et al. 2011. Magnetic properties of surface soils across the southern Tarim Basin and their relationship with climate and source material. Chinese Science Bulletin, 56(3): 290-296.

Zan J B, Fang X M, Yang S L, et al. 2015. Bulk particle size distribution and magnetic properties of particle-sized fractions from loess and paleosol samples in Central Asia. Geochemistry Geophysics Geosystems, 16(1): 101-111.

Zhang J, Zhang B H, Zhao H. 2015. Timing of amalgamation of the Alxa Block and the North China Block: Constraints based on detrital zircon U-Pb ages and sedimentologic and structural evidence. Tectonophysics, 668-669: 65-81.

Zhang X Y, Arimoto R, An Z S, et al. 1993. Atmospheric trace elements over source regions for Chinese dust: concentrations, sources and atmospheric deposition on the Loess Plateau. Atmospheric Environment. Part A. General Topics, 27(13): 20512067.

Zhu X M, Zhong D K, Yuan X J, et al. 2016. Development of sedimentary geology of petroliferous basins in China. Petroleum Exploration and Development, 43(5): 890-901. 